\title{
AMETAMORFOSE DO ORÇAMENTO PARTICIPATIVO: MUDANÇA DE GOVERNO E SEUS EFEITOS EM PORTO ALEGRE
}

\author{
Lúcio Rennó
}

\author{
Aílton Souza
}

\begin{abstract}
RESUMO
As diferentes experiências participativas surgidas no Brasil na década de 1990 colaboraram para que o país tornasse-se, como diz Tatagiba, em "um celeiro de experiências inovadoras de gestão". Um dos destaques dentre as várias experiências de governança é o Orçamento Participativo (OP): programa que ao longo dos anos tem sido palco de intensos debates e estudos e colecionado admiradores e críticos. Entretanto, apesar de sua fama e dos diversos estudos, poucos buscaram avaliar o desempenho e a sensibilidade do programa ao governo eleito no município. Este artigo investiga o programa de orçamento participativo do município de Porto Alegre entre 1989 e 2008, analisando especificamente a sensibilidade do programa às mudanças de governo entre as gestões do Partido dos Trabalhadores (PT) de 2001-2004 e do Partido do Movimento Democrático Brasileiro (PMDB) de 2005-2008. Ou seja, investigamos se a mudança de partido no controle da prefeitura, mantendo o OP em funcionamento, afetou, no entanto, seu desempenho. Nossa análise indica que o funcionamento do programa é bastante afetado pelo partido político que o implementa e que, portanto, o programa peca por baixa institucionalização, mesmo em seu caso de maior sucesso: o município de Porto Alegre.
\end{abstract}

PALAVRAS-CHAVE: orçamento participativo; avaliação de políticas públicas; Porto Alegre.

\section{INTRODUÇÃO}

A idéia de que é possível construir um projeto democrático baseado na extensão dos direitos, na abertura de espaços públicos com capacidade decisória e na participação política da sociedade renovou, nos anos 1990, o debate sobre aprofundamento da democracia na América Latina (AVRITZER, 2003; AVRITZER \& COSTA, 2004). A configuração desse cenário é concomitante e inspira a implantação de experimentos como a dos Orçamentos Participativos e dos Conselhos Gestores no Brasil; as Mesas de Concertación no Peru; as Auditorias Articuladas na Colômbia e os Concejos Autogestivos no México, que estreitaram o relacionamento entre a sociedade civil e a sociedade política (DAGNINO, OLVERA \& PANFICHI, 2007). Em meio a essas experiências, um dos destaques foi o programa "Orçamento Participativo" (OP), atualmente existente em diversas regiões do mundo (CABBANES, 2004).

O sucesso dessa experiência, que tem no caso de Porto Alegre seu exemplo mais reconhecido mundialmente, tornou o programa tema de amplos estudos e debates, principalmente sobre democracia participativa e esfera pública. O OP de Porto Alegre foi classificado como janela de oportunidade para mobilização política (ABERS, 2000); como um exemplo de radicalização da política (BAIERLE, 2003); como uma escola de cidadania (RIBEIRO \& GRAZIA, 2003); um híbrido democrático, que congrega participação e representação (AVRITZER \& PEREIRA, 2005) e como um mecanismo participativo de baixo para cima (AVRITZER, 2008) dentre outros.

Entretanto, embora essa literatura tenha avançado oferecendo inúmeras contribuições sobre o programa, a análise comparada do desempenho do OP entre distintas administrações é ainda tema relativamente pouco explorado (NYLEN, 2002; WAMPLER \& AVRITZER, 2004; RENNÓ, 2006; SCHENEIDER \& GOLDFRANK, 2006; RENNÓ \& AMES, 2010). Ainda menos explorada é a avaliação do funcionamento do programa sob a direção de diferentes administrações partidárias em um mesmo município. Esse tipo de estudo é interessante porque cria uma situação quasi-experimental: 
quando se insere um estímulo, no caso a mudança de partido no governo, e mede-se o impacto dessa mudança na variável de interesse, que aqui é o funcionamento do $\mathrm{OP}^{1}$.

Nesse sentido, o objetivo deste artigo é analisar o desempenho do Orçamento Participativo do município de Porto Alegre entre 1989 e 2008, contrastando, principalmente, a sensibilidade do OP à mudança de governo ocorrido em 2004, quando o Partido dos Trabalhadores (PT) perde a prefeitura para José Fogaça, então no Partido Popular Socialista (PPS). Para isso, nossa análise enfoca as possíveis mudanças em cinco dimensões do OP: participação popular, atendimento de demandas, "empowerment", "transparência" e "accountability".

Estudamos essas cinco dimensões por motivos diversos. A participação é e sempre foi tema preponderante nos trabalhos clássicos sobre o $\mathrm{OP}$ (ABERS, 1997; 2000; SANTOS, 1998; AVRITZER, 2003; 2008; FEDOZZI, 2001; 2005; 2007; BAIOCHI, 2003; BAIERLE, 2005; 2007; WAMPLER, 2007). Analisá-la é, portanto, requisito fundamental para uma avaliação do funcionamento do programa. $\mathrm{O}$ atendimento a demandas públicas, embora menos enfocado que a questão da participação, é central para o bom funcionamento do programa, que visa também reverter as prioridades do governo e alocar recursos públicos onde eles são mais necessários. Participação e atendimento a demandas são também fatores bastante correlacionados.

A questão do empowerment, por sua vez, refere-se a ações destinadas a promoção de acesso dos excluídos e carentes aos bens e serviços indispensáveis à sua sobrevivência e à transferência de influência no processo decisório aos setores excluídos (ROWLANDS, 1995; ABERS, 1997; GOHN, 2004). Por último, mas não menos importante, a transparência e a accountability são elementos centrais do OP, principalmente no combate ao clientelismo e na tentativa de estabelecer mecanismos universais de acesso aos recursos públicos (ABERS, 2000). $\mathrm{O} O \mathrm{OP}$, ao tentar promover maior transparência na alocação de recursos públicos e eliminar a presença de intermediários nas decisões do

\footnotetext{
1 Para uma discussão sobre experimentos naturais, ver Babbie (2004).
}

governo, objetiva aumentar o controle popular sobre os gastos públicos e fortalecer a accountability. Assim, o próprio OP passa a ser um mecanismo de prestação de contas.

Este artigo toma como ponto de partida a hipótese de que governos não petistas tendem a ter menos sucesso na condução do programa de OP nas dimensões acima (ABERS, 1997; NYLEN, 2003; WAMPLER \& AVRITZER, 2004; BAIERLE, 2008; WAMPLER, 2008). Assim, nossa pergunta principal é até que ponto o programa de OP é sensível ao partido que está no poder? O caso de Porto Alegre, mais uma vez, torna-se fundamental para responder essa pergunta, pois permite contrastar administrações de diferentes partidos que optaram por manter o programa em funcionamento.

Empreendemos uma análise documental e realizamos entrevistas com atores específicos, historicamente vinculados ao programa, para avaliar as categorias analíticas, descritas acima, que orientam este artigo. Desenvolvemos nosso argumento em três estágios, além desta introdução. A primeira parte é dedicada à revisão da literatura sobre o programa de OP e do panorama de competição política do município a partir de suas disputas eleitorais. Damos atenção neste aspecto a um dos instrumentos concorrentes com o programa de OP implantados pelo governo Fogaça: o Governança Solidária Local (GLS). Na segunda parte, apresentamos os resultados empíricos da pesquisa analisando o desempenho do OP a partir de variáveis quantitativas e qualitativas. Em seguida, passamos para nossas considerações finais.

II. ORCAMENTO PARTICIPATIVO, DESENVOLVIMENTO INSTITUCIONAL COMPARADO E A COMPETIÇÃO POLÍTICA EM PORTO ALEGRE

Orçamento participativo (OP), presupuesto participativo (PP) ou participatory budgeting $(\mathrm{PB})$ são algumas das denominações do programa participativo brasileiro mais conhecido internacionalmente. O programa em questão foi definido de acordo com as várias interpretações oferecidas pela teoria especializada (ABERS, 1997; SANTOS, 1998; FEDOZZI, 2001; BAIOCCHI, 2003; NYLEN, 2003; WAMPLER, 2007; AVRITZER, 2008) como um processo decisório que envolve a participação direta da 
população na distribuição de recursos públicos a serem aplicados na comunidade durante todo o ano fiscal. Nesse contexto, o OP é tido como um efetivo instrumento de democracia direta, pois oferece aos cidadãos a oportunidade para a participação, deliberação, debate e influência na alocação dos recursos públicos orçamentários. Considerado por Avritzer e Pereira (2005) como um programa híbrido pela existência de soberania partilhada, reintrodução de elementos de participação na tomada de decisão e de autoregulação soberana, os programas de OP ocuparam o centro do debate da democracia participativa, ao menos no Brasil.

Precedido por experiências decorrentes das gestões democráticas participativas ainda das décadas de 1970 e 1980 em cidades como Piracicaba e Diadema (SP); Lages (SC); Pelotas (RS); Boa Esperança e Vila Velha (ES), a mais famosa experiência do OP, próximo ao modelo aplicado até hoje na maioria dos casos, surge em 1989 na cidade de Porto Alegre (RS).

O processo de formação do OP emerge da junção de, ao menos, dois fatores importantes: o aumento de recursos municipais ${ }^{2}$ e a gestão de partidos considerados de esquerda nos governos locais. O papel desempenhado pelos partidos de esquerda, em especial o PT, que ascendeu ao poder municipal com a política da participação popular (TEIXEIRA \& ALBUQUERQUE, 2006) e o "crescimento do número de cidades (inclusive importantes capitais de estados que readquiriram o direito de eleger seus prefeitos) que passaram a ser administradas por forças políticas progressistas e democráticas" (FEDOZZI, 2005, p. 143) ampliou o espaço para inovações nas práticas de governança e abriu espaço para a incorporação de inovações advindas de demandas da sociedade civil (idem; AVRITZER, 2003). Assim sendo, o processo de democratização e descentralização decisória ensejado pela redemocratização do país ampliou as oportunidades para que organizações da sociedade civil interviessem na gestão de políticas públicas,

2 Esse aumento deve-se, "sobretudo, à elevação dos percentuais do Fundo de Participação dos Estados e do Distrito Federal (FPE) e do Fundo de Participação dos Municípios (FPM), que passaram, respectivamente, de $14 \%$ e $16 \%$, em 1985 , para $21,5 \%$ e $22,5 \%$, em 1988 " (BRASIL, 2003, p. 10-11). na alocação e controle do orçamento público, principalmente a partir Constituição Federal de 1988.

Outro componente central desse cenário é o fortalecimento do papel dos movimentos sociais e da sociedade civil no que tange a organização, mobilização, reivindicação de direitos e luta pela ampliação da agenda democrática. Esse papel, de acordo com Fedozzi (2001), esteve relacionado aos movimentos associativos, organizações não governamentais (ONGs), comunidades eclesiásticas e os partidos políticos ligados às lutas sociais e à redemocratização do país.

Ademais, contribui para o sucesso de práticas inovadoras de governança, tal qual o OP em Porto Alegre, o alto grau de associativismo e de capital social, que faz da região um diferencial em relação ao restante do país (AVRITZER, 2003).

Entretanto, é a capacidade de transformação política e social do programa implantado em Porto Alegre que leva a experiência a ser vista, "tanto na literatura nacional como na estrangeira, como um exemplo de instrumento de promoção do 'bom governo" (SOUZA, 2001, p. 84). Esse novo instrumento de participação, ainda em sua primeira década de funcionamento, foi copiado e implementado por governos de diversas regiões, atraído principalmente pelo que Abers (1997) e Fedozzi (2005) denominaram "efeito demonstração", ou seja, a capacidade que o programa teve de atrair a comunidade para a participação e a deliberação pública.

Portanto, o que vemos no presente é uma proliferação de experiências participativas pelo mundo, nos moldes do OP (CABBANNES, 2004; WAMPLER, 2007). No Brasil o OP também se expandiu, passando a ser adotado por governos não petistas e, até mesmo, por governos não ligados à esquerda ${ }^{3}$. Esse cenário contribuiu para uma nova linha de pesquisa focada nos programas de OP em perspectiva comparada. Wampler e Avritzer (2004), por exemplo, comparam o OP

3 O marco dessa nova conjuntura, segundo Ribeiro e Grazia (2003), situa-se entre 1997-2000, quando 50\% das experiências do OP no Brasil eram conduzidas por governos não petistas como Partido Democrático Trabalhista (PDT), PSDB, PFL, Partido Progressista Brasileiro (PPB) entre outros. Período considerado pelos autores como de nacionalização do programa. 
de três cidades em diferentes administrações e estágios do programa: Porto Alegre, Belo Horizonte e Recife (PT, PT-PSB, PMDB-PFL, respectivamente $)^{4}$. Para esses autores, Recife (PMDB-PFL) apresenta o menor sucesso no que tange a mobilização social e a participação popular no programa. Ribeiro e Grazia (2003) também indicam que administrações petistas foram mais bem sucedidas em alguns aspectos do programa, principalmente relativos à mobilização da participação.

Em outros trabalhos de natureza comparativa, principalmente entre cidades com governos de mesma sigla política, os resultados são variados. Entretanto, dois elementos têm sido apontados como fatores que influenciam os resultados do OP: as diversas características do município e o grau de comprometimento orçamentário da prefeitura com o programa (NYLEN, 2002; 2003; WAMPLER, 2003; TEIXEIRA \& ALBUQUERQUE, 2006).

Mais recentemente, os estudos comparados tem ampliado o número de casos incluídos na análise, passando a fazer análises estatísticas do impacto do OP em questões fiscais e políticas (ZAMBONI, 2007; BIDERMAN \& SILVA, 2008; SPADA, 2009) ${ }^{5}$. Esses estudos têm se mostrado menos otimistas com o efeito do OP do que aqueles que se resumem a poucos casos.

Contudo, conforme dito antes, todas essas pesquisas ainda não investigaram como a mudança de partido no governo, em um mesmo município, ambas mantendo o $\mathrm{OP}$ em funcionamento, afetou o desempenho do programa. Assim, tiramos vantagem da situação político-eleitoral de Porto Alegre, o prototípico exemplo de sucesso do OP, para avaliar como a derrota eleitoral do PT em 2004, e a entrada de José Fogaça na prefeitura, influenciou o funcionamento do OP porto-alegrense. Portanto,

\footnotetext{
4 Partido dos Trabalhadores (PT), Partido Socialista Brasileiro (PSB), Partido do Movimento Democrático Brasileiro (PMDB) e Partido da Frente Liberal (PFL).

5 Um dos destaques dessa corrente foi o estudo de Zamboni (2008), que em pesquisa realizada de 20002004, apontou que o OP "não é condição suficiente para melhor governação" (idem, p. 34). Entretanto, salientou não rejeitar o OP como uma política aconselhável de boa governança.
}

nossa comparação é entre distintas administrações em uma mesma cidade, algo que ainda não foi explorado pela literatura de política comparada sobre o OP.

Embora o OP obtenha crescente respaldo no cenário internacional, em Porto Alegre é ainda um tema polêmico, e invariavelmente tornou-se um dos principais assuntos nos períodos eleitorais. O OP contribuiu para vitórias consecutivas do PT em Porto Alegre, sendo ponto de discórdia na efervescente competição entre os partidos de oposição e situação no município. No entanto, as diversas vitórias petistas e o uso eleitoral do OP "teriam acirrado os ânimos da política local e levado os partidos de oposição e seu eleitorado a uma "demonização" do PT e do seu modo de fazer política" (DIAS, 2008, p. 247). Dessa forma, o OP tornou-se foco de intensos debates e de manifestações distintas situadas basicamente em dois polos: de um lado, os opostos ao PT que enfatizam o programa como um instrumento partidário que destrói a democracia representativa; de outro, os que defendem o programa como paradigma de democracia direta (SCHENEIDER \& GOLDFRANK, 2006).

A dualidade e o controle do OP pelo PT em 2004 foi posta à prova quando a oposição assume estratégia de campanha diferente, defendendo a "participação popular" e a continuação do programa de orçamento participativo. No primeiro turno da eleição de 2004, a força do Partido dos Trabalhadores ainda era visível, e o partido vence com uma diferença de $25 \%{ }^{6}$ dos votos válidos sobre o segundo colocado, José Fogaça do PPS. Já no segundo turno esse cenário reverte-se e o Partido dos Trabalhadores perde as eleições.

Para Dias, "José Fogaça saiu vitorioso das urnas e pôs fim à era política do PT em Porto Alegre, mas não sem antes comparecer a uma convocação do Conselho do Orçamento Participativo para manifestar publicamente sua intenção de dar continuidade à consulta popular para a distribuição dos recursos públicos municipais" (DIAS, 2004, p. 253).

Portanto, o OP ainda mantém relevância eleitoral em 2004, mas deixa de ser uma "propriedade", um diferencial do PT. Prova disso

\footnotetext{
6 Essa porcentagem representa aproximadamente 76 mil votos.
} 
é que nas eleições de 2008 Fogaça novamente repete a façanha e reelege-se Prefeito, agora pelo PMDB, mais uma vez em disputa acirrada com o PT. Contudo, diferentemente da eleição anterior, Fogaça faz campanha após ter mantido o OP em funcionamento, apesar de não mais com a centralidade que o programa tinha nas administrações petistas.

A esse respeito, outro aspecto importante da recente disputa política em Porto Alegre emerge a partir da implementação de novos instrumentos políticos concorrentes com o OP. O mais marcante advém do primeiro mandato de Fogaça com a criação do programa de Governança Solidária Local (GSL), que em linhas gerais busca criar uma cultura de solidariedade e cooperação nas comunidades locais com base na formação de parcerias. Assim, subsiste em Porto Alegre duas marcas de governança: o OP vinculado ao petismo e a GLS símbolo do atual governo peemedebista.

Podemos supor que a mudança de enfoque na administração Fogaça, apesar de manter o OP em funcionamento, tenha afetado o funcionamento desse programa. Se o OP passa a ocupar posição secundária na plataforma de governo de Fogaça, nada mais natural que o programa passe a ser menos eficiente na alocação de recursos e que estimule menos participação. Também é possível pensar que as mudanças nesses quesitos também levem a uma queda nas expectativas de que o OP gere empowerment, transparência $\mathrm{e}$ accountability. Contudo, esses últimos fatores devem ser menos influenciados, pois não há mudanças significativas na metodologia do OP com Fogaça.

\section{ANÁLISE DOS 20 ANOS DO OP DE POR- TO ALEGRE: CATEGORIAS ANALÍTICAS EDADOS}

Apesar de amplamente estudado, conforme enfatizamos anteriormente, ainda não há pesquisas sistemáticas que diferenciam o funcionamento do OP em um mesmo município, quando há mudança de partido na administração local e manutenção do programa. Mas quais fatores devem ser comparados nas duas administrações?

Wampler (2003) apontou para cinco aspectos que determinam o bom funcionamento do OP: o desenho institucional, o compromisso político do governo, a densidade da sociedade civil, o tempo de duração do programa e os recursos financeiros do município. Para entendermos melhor as mudanças do OP, centraremos nossa análise em algumas dessas mesmas categorias, acrescentando outras que nos parecem igualmente importantes. O estudo, assim, concentra-se nas cinco dimensões que mencionamos anteriormente: participação popular; atendimento de demandas; empowerment popular; transparência e a accountability do programa.

Para avaliar a categoria participação no OP, utilizamos dados disponibilizados pela Prefeitura Municipal. Vale salientar que para o computo dessa variável é utilizado o credenciamento de cada participante nas plenárias ou nos fóruns temáticos do programa. No caso dos efeitos do atendimento das demandas públicas, tomamos como parâmetro de avaliação as principais demandas, ou as mais priorizadas, segundo votação divulgada nos planos de investimentos anuais entre 2001 a 2008. Estabelecidas as cinco primeiras demandas mais importantes a para população do município, avaliamos o desempenho do governo em seu tratamento de 1989 a 2008 a partir de dois instrumentos: o próprio Plano de Investimento divulgado anualmente a cada ciclo do OP e os dados de prestação de contas disponibilizados online no sitio eletrônico da Prefeitura Municipal de Porto Alegre. Em ambas as fontes encontramse informações sobre o estágio em que as demandas podem estar: concluídas, em andamento ou paralisadas.

Já para o caso do empowerment, transparência e a accountability, e em função de serem conceitos relativamente difíceis de serem mensurados, é importante frisar que para que sejam efetivos, dependem de como são percebidos pela população e por atores políticos da sociedade civil. Assim, todos os três precisam ser avaliados por meio das percepções declaradas desses atores chave. Portanto, para a análise dessas três variáveis a técnica empregada foi a de entrevistas com dois grupos de atores: entidades representativas e associações de moradores ${ }^{7}$. O primeiro é composto por entidades: Federação Rio Grandense de Associações Comunitárias e de Moradores de Bairros (Fracap); União de Associações de Moradores de Porto Alegre (Uampa) e a ONG

\footnotetext{
7 A título operacional, nas entrevistas referimo-nos a empowerment como poder de decisão e a accountability como prestação de contas.
} 
A METAMORFOSE DO ORÇAMENTO PARTICIPATIVO

Cidade - todas com papel histórico e atual importante no programa de OP. O segundo grupo é constituído pelas associações de moradores: Parque dos Maias, Cavalhada, Auxiliadora, Mario Quintana-Nacipaz e Vila São Judas Tadeu. É importante mencionar que as associações de moradores de Porto Alegre são componente central do funcionamento do OP (FEDOZZI, 2007). A seleção dessas associações tiveram por base as indicações feitas pelos representantes das entidades do primeiro grupo e foi feita de modo a evitar a seleção apenas de associações alinhadas ao PT ou que apresentem qualquer viés favorável ou contrário ao governo Fogaça. As entrevistas foram realizadas com pessoas que ocupam posição de destaque nas organizações que representam, exercendo cargo na Diretoria, Coordenação ou mesmo a Presidência da entidade ou associação ${ }^{8}$.

Portanto, trata-se de um estudo que mescla técnicas de pesquisa quantitativas e qualitativas, sem qualquer hierarquização entre elas, para melhor avaliar as diferentes dimensões do funcionamento do OP em Porto Alegre. Algumas dimensões são mais apropriadamente analisadas usando dados quantitativos, enquanto outras exigem dados qualitativos. E, na verdade, essas dimensões claramente influenciam-se mutuamente, assim, deixar de avaliar uma ou outra resultaria em um quadro provavelmente enviesado do funcionamento do OP. Para evitar esse problema, adotamos uma estratégia que combina técnicas de pesquisa distintas.
III.1. Participação popular

Uma das principais características do orçamento participativo, principalmente pelo reconhecimento que obteve de organismos multilaterais como o Banco Mundial e Organização das Nações Unidas (ONU-Habitat), é o grau de participação popular no OP. Em Porto Alegre, onde o OP resiste a vários governos, o número de participantes do programa apresentou uma tendência de crescimento contínuo, com início de inflexão em 2002. Entretanto, cabe inicialmente enfatizar quem é o público do programa. Fedozzi (2007) aponta que a maioria dos participantes do OP possui as seguintes características: (i) $54,5 \%$ dos participantes das plenárias regionais é feminina; (ii) $21,7 \%$ estão na faixa etária entre 42 e 49 anos; (iii) 47,6\% dos participantes possuem ensino fundamental total ou parcial; (iv) $55,7 \%$ autodeclararam-se de raça ou etnia branca; (v) $39,4 \%$ possuem renda familiar de até dois salários mínimos; (vi) $24 \%$ têm como profissão ou ocupação o cargo de Servente, Auxiliar de Serviços gerais, Cozinheiro etc.; (vii) $21,9 \%$ são autônomos; (viii) $54,6 \%$ participam de associações de moradores; (ix) 49,3\% não possuem preferência partidária declarada.

Ou seja, trata-se de um público variado, mas com alta participação de pessoas de baixa renda e escolaridade e que estão engajadas em associações de bairro. No gráfico abaixo apontamos os índices acumulados da participação no OP em plenárias regionais e temáticas.

GRÁFICO 1 - PARTICIPAÇÃO POPULAR NO ORÇAMENTO PARTICIPATIVO: PORTO ALEGRE (1989-2009)

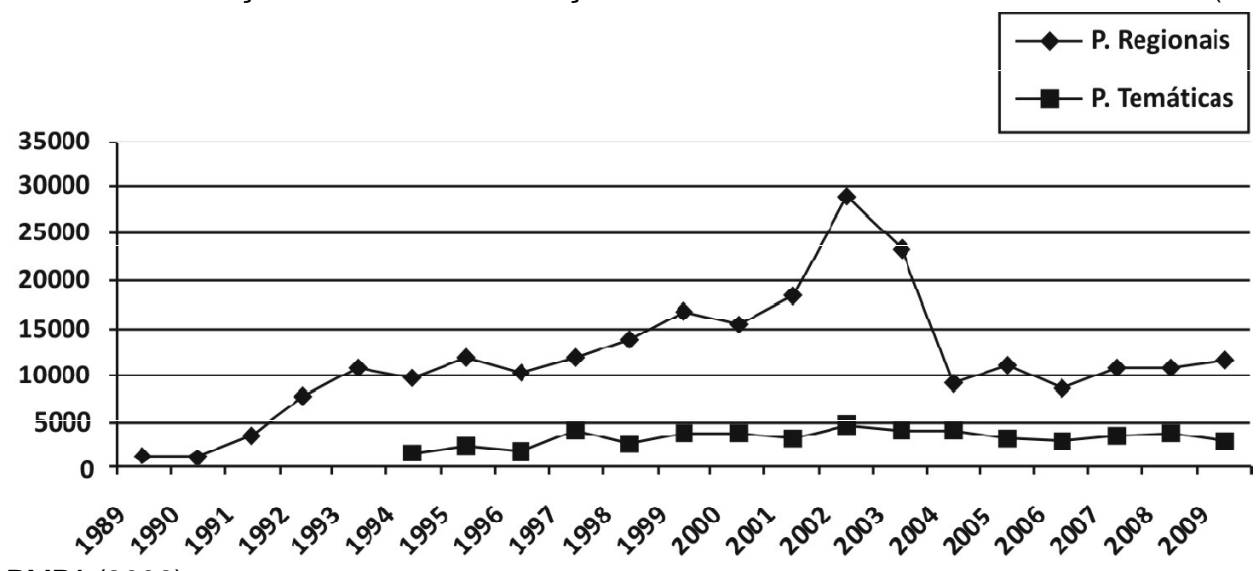

FONTE: PMPA (2009).

8 Para aumentar a confiabilidade dos dados e proteger os entrevistados, preservamos suas identidades.

240 
Torna-se claro no gráfico acima que a participação nas sessões plenárias regionais do OP vinha em uma crescente desde 1990 e atinge seu ápice em 2002. Em 2003 aponta uma sensível queda chegando ao último ano da administração petista, em 2004, a níveis similares aos de 1992. Esse valor mantém-se durante toda a primeira administração de José Fogaça. É possível observar claramente que apesar da última gestão petista, de 2001-2004, apresentar uma queda brusca na participação no ano de 2003 e 2004, a gestão também obtém o maior número de participantes da história do OP em 2002. Não obstante, esses dados demonstram uma ruptura no padrão crescente de participação popular no OP até 2002 e a importância secundária que ele assume após 2004.

Porém, é interessante analisar que em 2002 houve grande número de demandas, claramente relacionado à ampla participação, já que esta é requisito para que uma demanda seja selecionada e possa ser incorporada no orçamento do ano seguinte. É possível assim especular que a crise financeira e a incapacidade de cumprir as demandas em 2003 e 2004, podem ter contribuído para a queda do número de participantes. Ou seja, é possível especular que a queda na participação já em 2003 seja resultado da dificuldade da prefeitura em implementar as decisões tomadas no OP de 2002. Passemos a essa questão agora.

\section{III.2. Demandas no orçamento participativo}

A capacidade que os governos possuem de responder às demandas públicas da sociedade tem figurado como um dos sinônimos da efíciência da máquina pública e, conseqüentemente, de maior satisfação popular com o governo. Embora não apresentamos aqui pesquisas de opinião que

\footnotetext{
9 No processo de votação, os votos dos participantes das assembléias regionais ou temáticas são convertidos em pontos, sendo selecionada para execução a demanda com
} maior pontuação entre as micro-regiões. possam fundamentar tal prerrogativa, é possível afirmar que no OP de Porto Alegre esse princípio também se mantenha. Portanto, participação continuada e crescente no OP está condicionada à implementação com sucesso das demandas feitas em anos anteriores.

Buscando avaliar o padrão de resposta às demandas formuladas via OP, apresentamos um panorama das principais demandas processadas no OP porto-alegrense ao longo dos anos. Enfocamos demandas de dois tipos: gerais e temáticas. Estas, por sua vez, dividem-se em três categorias classificatórias: (i) demanda concluída - que se refere a todas as demandas da área/órgão votadas e executadas; (ii) demanda em andamento - inclui as demandas votadas e que estão em curso ou em fase de conclusão; (iii) demanda paralisada - refere-se às demandas que, por algum motivo - falta de recursos, entraves políticos, problemas técnicos ou jurídicos - aguardam medidas para sua continuidade.

Embora as demandas do OP dirijam-se a diferentes áreas, na presente discussão abordamos apenas as áreas de educação, obras e viação, saúde, assistência social e de habitação. As referidas áreas ou órgãos estão vinculados à administração direta e indireta da Prefeitura Municipal de Porto Alegre. Essas áreas não foram escolhidas aleatoriamente, mas por receberem maior votação nas assembléias e fóruns do programa ${ }^{9}$. Assim, trabalhamos com as demandas mais relevantes do OP de Porto Alegre.

A partir dos resultados das votações nas reuniões do OP, conforme demonstramos no quadro abaixo, analisamos as cinco principais áreas, das 27 existentes ${ }^{10}$. Sendo três da administração pública direta e duas da indireta.

10 A prestação de contas está disponível no sítio virtual da Prefeitura Municipal de Porto Alegre (2011). 
TABELA 1 - ORDENAMENTO DAS PRIORIDADES TEMÁTICAS DO OP POR ANO DISTRIBUÍDAS POR ÓRGÃOS CONFORME VOTAÇÃO RECEBIDA EM PLENÁRIAS REGIONAIS: PORTO ALEGRE (2001-2008)

\begin{tabular}{|c|c|c|c|c|c|c|c|c|}
\hline Anos & 2001 & 2002 & 2003 & 2004 & 2005 & 2006 & 2007 & 2008 \\
\hline $\begin{array}{l}\text { Departamento } \\
\text { Municipal de } \\
\text { Habitação } \\
\text { (Demhab) }\end{array}$ & $\begin{array}{l}2^{\circ}-32 \\
\text { pontos }\end{array}$ & $\begin{array}{l}1^{\circ}-40 \\
\text { pontos }\end{array}$ & $\begin{array}{l}1^{\circ}-54 \\
\text { pontos }\end{array}$ & $\begin{array}{l}1^{\circ}-55 \\
\text { pontos }\end{array}$ & $\begin{array}{l}1^{\circ}-57 \\
\text { pontos }\end{array}$ & $\begin{array}{l}1^{\circ}-56 \\
\text { pontos }\end{array}$ & $\begin{array}{l}1^{\circ}-58 \\
\text { pontos }\end{array}$ & $\begin{array}{l}1^{\circ}-52 \\
\text { pontos }\end{array}$ \\
\hline $\begin{array}{l}\text { Secretaria } \\
\text { Municipal } \\
\text { Eđucação } \\
\text { (SMED) }\end{array}$ & $\begin{array}{l}4^{\circ}=22 \\
\text { pontos }\end{array}$ & $\begin{array}{l}2^{\circ}=30 \\
\text { pontos }\end{array}$ & $\begin{array}{l}2^{\circ}=30 \\
\text { pontos }\end{array}$ & $\begin{array}{l}3^{\circ}=24 \\
\text { pontos }\end{array}$ & $\begin{array}{l}2^{\circ}=31 \\
\text { pontos }\end{array}$ & $\begin{array}{l}2^{\circ}=42 \\
\text { pontos }\end{array}$ & $\begin{array}{l}2^{\circ}=28 \\
\text { pontos }\end{array}$ & $\begin{array}{l}2^{\circ}=25 \\
\text { pontos. }\end{array}$ \\
\hline 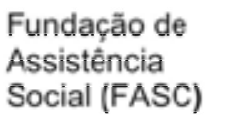 & $\begin{array}{l}6^{\circ}-18 \\
\text { pontos }\end{array}$ & $\begin{array}{l}4^{\circ}-19 \\
\text { pontos }\end{array}$ & $\begin{array}{l}4^{\circ}-18 \\
\text { pontos }\end{array}$ & $\begin{array}{l}2^{\circ}-29 \\
\text { pontos }\end{array}$ & $\begin{array}{l}3^{\circ}-20 \\
\text { pontos }\end{array}$ & $\begin{array}{l}4^{\circ}-16 \\
\text { pontos }\end{array}$ & $\begin{array}{l}3^{*}-24 \\
\text { pontos }\end{array}$ & $\begin{array}{l}3^{\circ}-24 \\
\text { pontos }\end{array}$ \\
\hline $\begin{array}{l}\text { Secretaria } \\
\text { Municipal de } \\
\text { Obras e Viaçăo } \\
\text { (SMOV) }\end{array}$ & $\begin{array}{l}1^{\circ}-34 \\
\text { pontos }\end{array}$ & $\begin{array}{l}3^{\circ}-30 \\
\text { pontos }\end{array}$ & $\begin{array}{l}3^{\circ}-24 \\
\text { pontos. }\end{array}$ & $\begin{array}{l}4^{\circ}-18 \\
\text { pontos }\end{array}$ & $\begin{array}{l}3^{\circ}-20 \\
\text { pontos }\end{array}$ & $\begin{array}{l}5^{\circ}-11 \\
\text { pontos }\end{array}$ & $\begin{array}{l}4^{\circ}-19 \\
\text { pontos. }\end{array}$ & $\begin{array}{l}5^{\circ}-22 \\
\text { pontos }\end{array}$ \\
\hline $\begin{array}{l}\text { Secretaria } \\
\text { Municipal de } \\
\text { Saúdōe (Sivis) }\end{array}$ & $\begin{array}{l}5^{\circ}-19 \\
\text { pontos }\end{array}$ & $\begin{array}{l}5^{\circ}-17 \\
\text { pontos }\end{array}$ & $\begin{array}{l}5^{\circ}-11 \\
\text { pontos }\end{array}$ & $\begin{array}{l}5^{\circ}-17 \\
\text { pontos }\end{array}$ & $\begin{array}{l}6^{\circ}-06 \\
\text { pontos. }\end{array}$ & $\begin{array}{l}3^{\circ}=19 \\
\text { pontos }\end{array}$ & $\begin{array}{c}5^{\circ}= \\
12 \text { pontos. }\end{array}$ & $\begin{array}{l}4^{\circ}-23 \\
\text { pontos }\end{array}$ \\
\hline
\end{tabular}

FONTES: Os autores, a partir dos planos de investimento do OP de 2001 a 2008 (PREFEITURA MUNICIPAL DE PORTO ALEGRE, 2001; 2002; 2003; 2004; 2005; 2006; 2007; 2008).

A partir da análise da votação realizada foi possível identificar que as demandas mais votadas entre 2001-2008 concentram-se nos seguintes órgãos da administração direta: Secretaria Municipal de Educação (SMED); Secretaria Municipal de Obras e Viação (SMOV); Secretaria Municipal de Saúde (SMS); da administração indireta: Fundação de Assistência Social e Cidadania (FASC) e o Departamento Municipal de Habitação (Demhab).

O Demhab, o órgão mais votado e um dos principais campos de demandas de Porto Alegre em função da carência de moradias e da necessidade de regularização - executa a política habitacional do município. Um dos seus objetivos é viabilizar acesso à moradia digna e ao solo urbano regularizado à população. Já a SMED, segunda colocada nas votações, responsabilizase atualmente por cerca de 55000 alunos, distribuídos entre educação infantil, ensino fundamental, ensino médio e educação de jovens e adultos. O tema da educação, que remete às demandas dessa secretaria, ocupa também um lugar de destaque como prioridade para os participantes do programa.
A FASC, terceira mais votada, foi criada em 2000 vindo a substituir a antiga Fundação de Educação Social e Comunitária (FESC). A FASC desenvolve programas e serviços para a população mais vulnerável do município em conformidade com a Lei Orgânica de Assistência Social (LOAS). Já a SMOV, quarta mais votada, foi criada em dezembro de 1955 e atua na coordenação, elaboração e execução de projetos de obras viárias, manutenção de vias urbanas, aprovação de projetos prediais, fiscalização e aplicação de sanções a infratores. É também de competência dessa secretaria a implantação e manutenção do sistema de iluminação pública do município. Por fim, a SMS, quinto e último órgão mais votado, é o órgão gestor do Sistema Único de Saúde (SUS) de Porto Alegre tendo como uma de suas principais atribuições a coordenação dos serviços, das ações, e das políticas de saúde da cidade. A secretaria, também estabelece ações integradas e intersetoriais com outros setores públicos e privados da esfera municipal, estadual e federal.

Estabelecido o processo de seleção dos órgãos e as áreas de abrangência do OP apresentamos no quadro abaixo as demandas totais do OP por gestão de governo. 


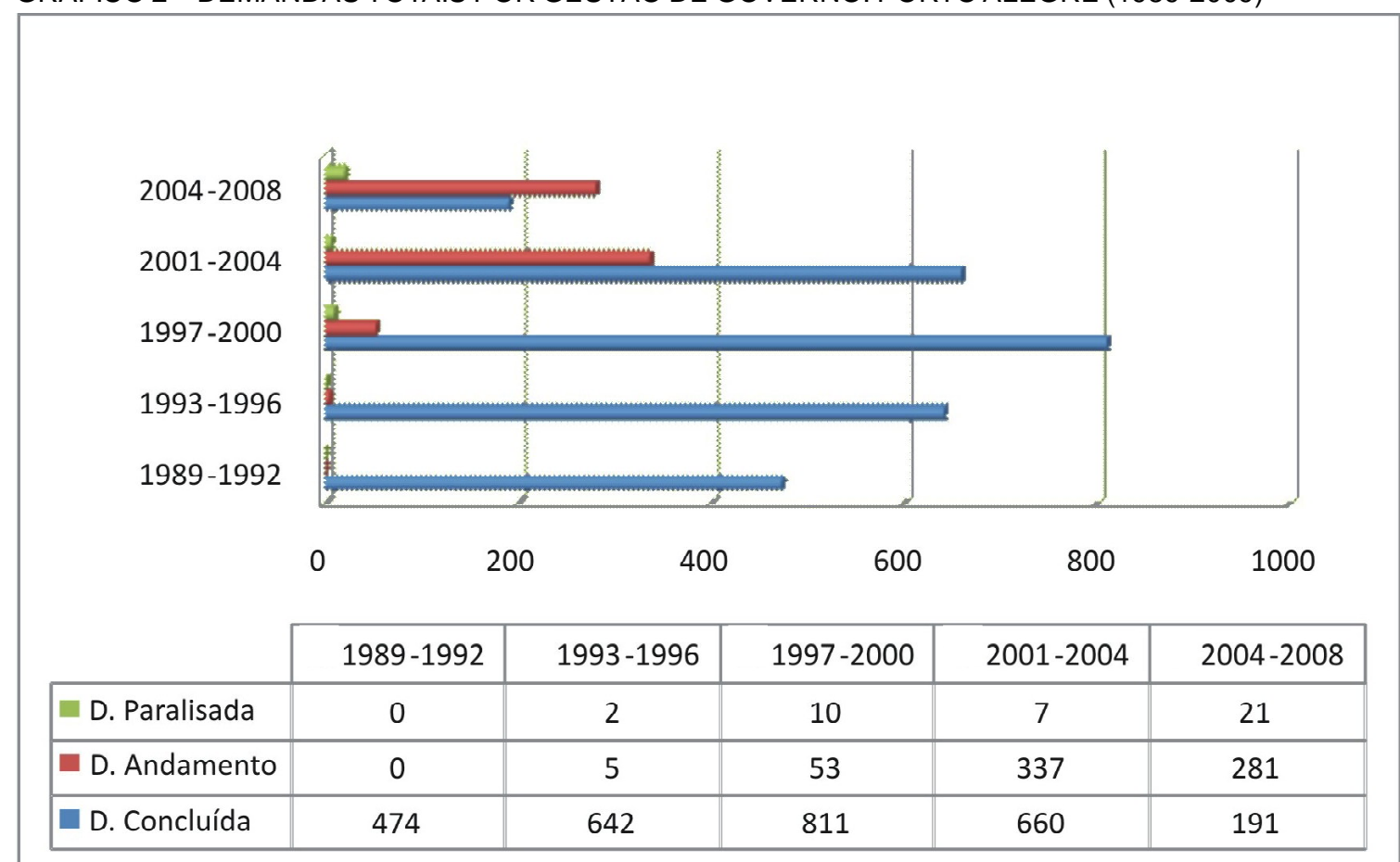

FONTES: Os autores, a partir dos planos de investimento do OP de 2001 a 2008 (PREFEITURA MUNICIPAL DE PORTO ALEGRE, 2001; 2002; 2003; 2004; 2005; 2006; 2007; 2008).

A partir desse quadro é possível analisar que na última gestão, de 2004 em diante, o índice de demandas concluídas foi relativamente baixo, enquanto as demandas em andamento superaram as demandas concluídas. O melhor desempenho observado, apesar de no período o OP ainda ser pouco expressivo, concentrou-se na primeira gestão, quando todas as demandas foram concluídas. Novamente, na segunda gestão, a conclusão de obras em muito supera as inacabadas. Já as duas últimas gestões petistas apresentam uma ruptura com as gestões anteriores, principalmente a gestão de 2001 a 2004. Nesse período, quase $33 \%$ das obras não foram concluídas e seguem em andamento. Ou seja, faz sentido argumentar que a não conclusão de obras está relacionada com a diminuição da participação no OP após 2002.

Mas é na gestão peemedebista após 2004 que essa situação agrava-se, com demandas em andamento somando $57 \%$ do total. Ou seja, repete-se aqui, no caso das demandas, o processo que havíamos observado antes, com uma mudança relevante da participação popular ainda no último mandato petista. Portanto, já desde 2001 há uma redução da capacidade do governo de responder às demandas definidas pelo OP.

$\mathrm{Na}$ seqüência apresentamos o total de demandas concluídas por departamento ou órgão de governo e por gestão. Podemos, dessa forma, observar se há uma mudança no padrão de investimento do governo em resposta às demandas feitas através do OP. 
GRÁFICO 3 - DEMANDAS CONCLUÍDAS POR ÓRGÃO DO GOVERNO: PORTO ALEGRE (1989-2009)
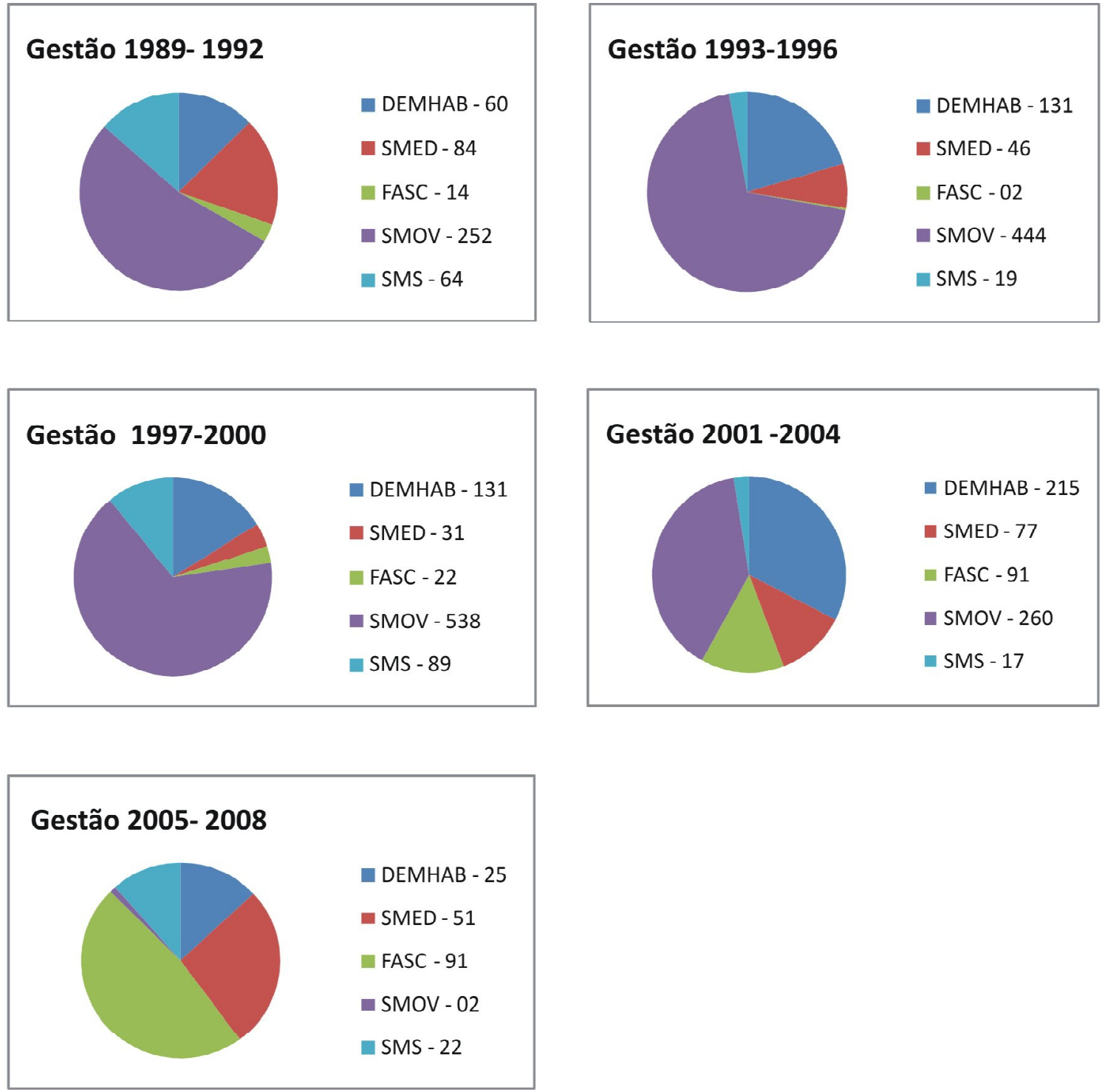

FONTES: Os autores, a partir dos planos de investimento do OP de 2001 a 2008 (PREFEITURA MUNICIPAL DE PORTO ALEGRE, 2001; 2002; 2003; 2004; 2005; 2006; 2007; 2008).

Com base nos dados acima, fica claro que as principais demandas priorizadas pelos governos petistas concentraram-se nas áreas de habitação (Demhab) e em obras de viação (SMOV). É possível crer que por opção de governo e agenda de partido, o PT tenha buscado atacar dois problemas que assolavam a região de Porto Alegre a longa data: a questão fundiária relativa ao alto contingente de habitantes em ocupação irregular e carência de infraestrutura das regiões mais pobres do município. Essas escolhas tem também uma dimensão temporal clara: precisam ser solucionadas antes de outras demandas pois refletem necessidades básicas das comunidades.
Já na gestão peemedebista de 2005 a 2008 o maior número de demandas atendidas pelo programa de OP concentra-se nas áreas de educação (SMED) e de assistência social (FASC). Essa mudança pode dever-se ao fato de as demandas fundiárias e de infraestrutura terem sido atenuadas pelo investimento feito nas administrações petistas anteriores ao primeiro governo de Fogaça. Contudo, também não podemos descartar que essa mudança possa refletir uma escolha de governo, principalmente se comparamos o perfil de gasto da última administração petista e do primeiro mandato do PMDB, não tão distantes no tempo. Ainda em sua última administração, o PT continua investindo em 
habitação e obras. Ou seja, é razoável supor que as mudanças no padrão de participação no OP tenham tido reflexo no padrão de gastos, já que na administração do PMDB, o perfil de gastos é bastante distinto.

Embora, o enfoque das demandas seja distinto nas administrações petistas e peemedebistas, a questão central parece estar relacionada à baixa capacidade de conclusão das demandas na última administração do PT e principalmente no primeiro mandato de Fogaça. Conforme aponta Baierle (2008), em 2004 na gestão do PT existiam 963 demandas do $\mathrm{OP}$ em aberto, número que saltou na gestão peemedebista para 1532. Esse acúmulo de demandas inacabadas ocorre concomitantemente à redução na participação no $\mathrm{OP}$.
Por outro lado, a questão pode ser técnica e estar relacionado à queda na capacidade de investimento no município e no OP. De acordo com o Banco Mundial (2008), e apresentado na figura abaixo, de 1990 a 1999, noventa por cento dos recursos orçamentários reservados para o OP foram investimentos. Porém, a partir de 2000, esse percentual fica abaixo dos $70 \%$. Ou seja, o comprometimento orçamentário da prefeitura com o OP, critério importante de avaliação do programa segundo Wampler (2003), parece ter arrefecido no passado recente, principalmente após 2004. A queda é bastante acentuada e brusca com a mudança de governo, indicando, de fato, que o OP perde espaço como um projeto da prefeitura na nova administração instalada em 2004.

GRÁFICO 4 - PORCENTAGEM DE INVESTIMENTO ANUAL EXECUTADO RELATIVO AOS VALORES DESTINADOS AO PROGRAMA DE OP DE PORTO ALEGRE (1999-2006)

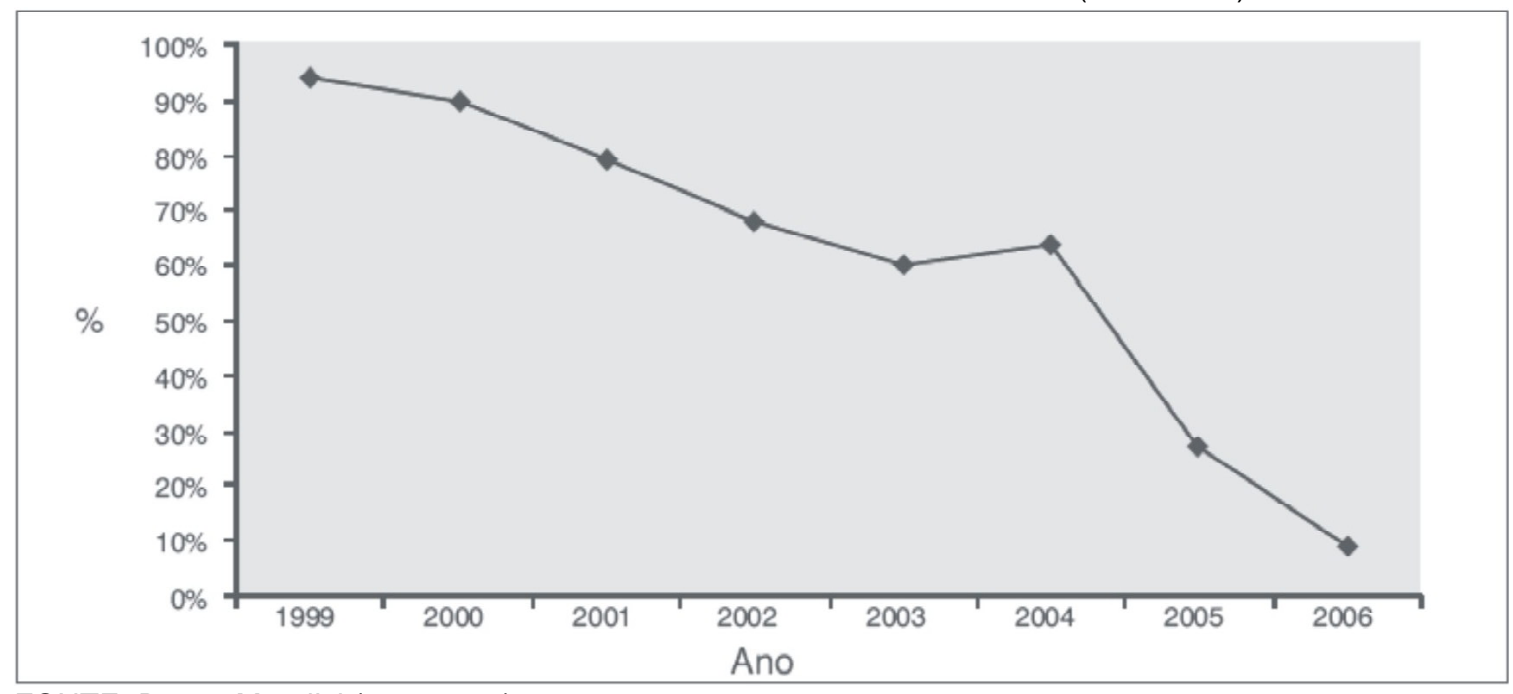

FONTE: Banco Mundial (2008, p. 7).

Em 2005-2006 a taxa dos investimentos executados cai drasticamente. Período, entretanto, em que aumenta o número de projetos classificados como "em andamento". Quando o percentual do orçamento disponível é muito pequeno ou as negociações entre governo e população não são transparentes, o OP pode transformar-se em um processo superficial, sem implicações políticas outras que não atender a interesses eleitoreiros (TEIXEIRA, 2003, p. 5). Aparentemente, não se gasta mais no OP, principalmente a partir de 2004, como se fazia antes, apesar de 2002 e 2003 já darem indícios de queda no investimento.
Mas o que essas porcentagens representam em valores financeiros?

Apresentamos na seqüência o gráfico de evolução dos investimentos no programa de OP entre os anos 1989-2008 em dólares. Os dados colocam em cheque a idéia de que houve queda nos investimentos, que é sugerida pelo Gráfico 4. Em média, a cifra de investimento correspondeu a $13,54 \%{ }^{11}$ do orçamento aprovado anualmente pela Câmara de Vereadores, mas esse valor cresceu em números absolutos apos 2004. Ou

$\overline{11}$ Média referente a 16 orçamentos anuais. 
seja, investe-se mais dinheiro no OP, apesar de queda na porcentagem de gastos.

Esses dados também colocam em cheque a idéia de que uma crise econômica tenha reduzido o investimento, já que a queda na porcentagem e aumento no valor absoluto indicam que houve processo de expansão da receita no município, em vez de retração, típica de momentos de crise. Assim, podemos descartar alguma justificativa de choque externo, causado por alguma crise econômica que extrapola as fronteiras do município, como explicação para a queda da participação e nos padrões de atendimento às demandas.

GRÁFICO 5 - EVOLUÇÃO ANUAL DE INVESTIMENTOS NO OP (EM MILHÕES DE DÓLARES); PORTO ALEGRE; 1989-2009)

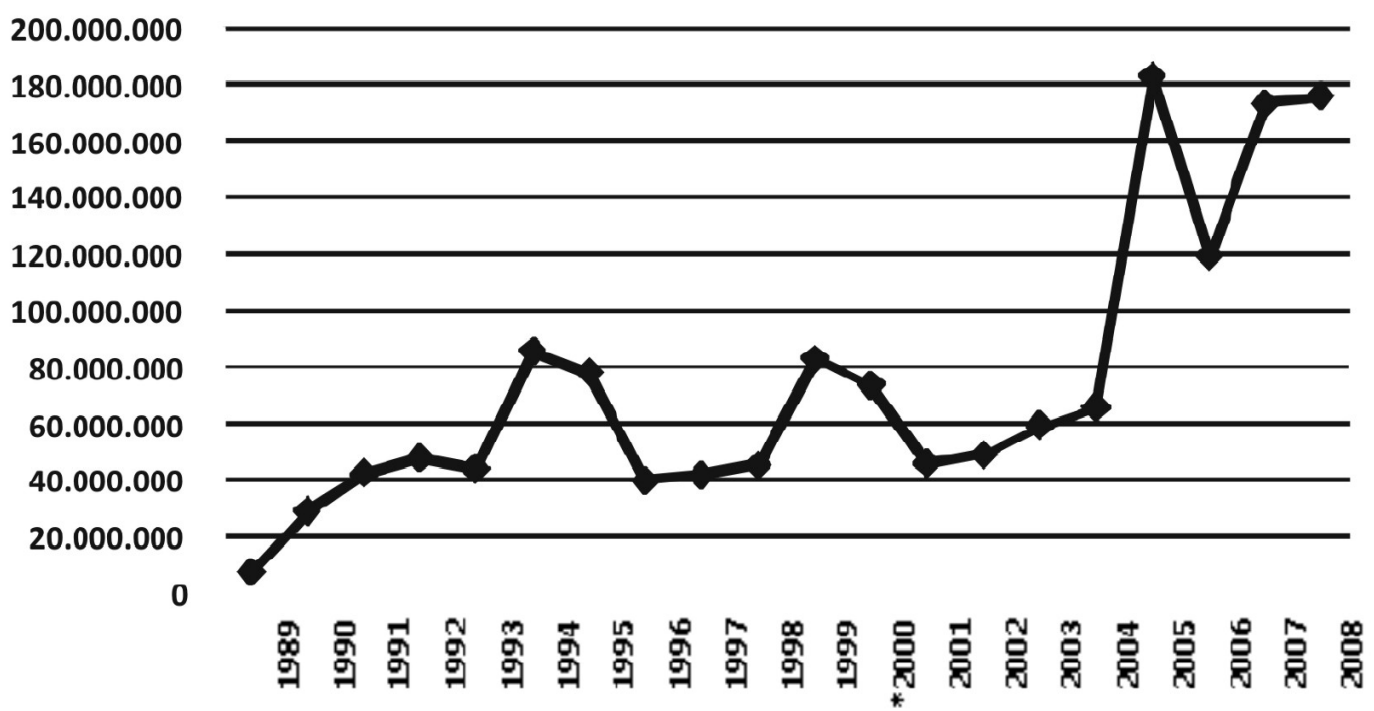

FONTE: os autores, a partir Plano de Investimento no OP editado pela PMPA (2009).

NOTA: Dados do ano 2000 relativos à média geral.

Quando avaliamos o conjunto dos dados de participação, atendimento de demandas e gastos verificamos ambigüidades entre queda na participação e conclusão de obras e crescimento dos gastos. Como explicar esse aparente paradoxo?

Uma das causas possíveis pode ser a mudança no perfil de investimento no programa. Assim, os investimentos podem estar destinados agora a demandas maiores, que exigem mais recursos e tempo para execução, gerando maior número de obras inacabadas. Esse panorama é possível, especialmente a partir de 2005, quando há algumas obras de grande investimento sendo realizadas no município de Porto Alegre. Entre elas destacamse: (i) o centro popular de compras, que faz parte do projeto de revitalização do centro; (ii) a Terceira Perimetral que possui $12,3 \mathrm{~km}$ e atravessa 20 bairros da capital, ligando as zonas Norte e Sul. Com investimentos que somam US\$ 84,1 milhões, financiados pelo Banco Interamericano de Desenvolvimento, sendo a construção realizada pela Secretaria Municipal de Obras e Viação; (iii) a obra do Conduto Álvaro Chaves-Goethe, que teve investimento na ordem de $\mathrm{R} \$ 59$ milhões e foi comandada pelo Departamento de Esgotos Pluviais (DEP), sendo uma das maiores drenagens urbana de Porto Alegre beneficiando diretamente 120 mil pessoas; (iv) o viaduto Leonel Brizola, na Terceira Perimetral sendo realizada pelo Departamento Municipal de Águas e Esgotos (DMAE).

Ou seja, as obras de infraestrutura, que eram centrais nos governos petistas até 2004, parecem ter consumido a maior parte do investimento do orçamento público por meio do OP. Entre 2005 e junho de 2009 foram concluídas 813 demandas de obras e serviços, sendo que $72 \%$ destas eram oriundas de gestões anteriores à do PMDB. Portanto, tanto a mudança no perfil das demandas 
concluídas quanto o maior número de obras ainda em andamento pode ser conseqüência da magnitude das obras que passaram a ser atendidas pela OP.

De qualquer forma, observamos mudanças relevantes no perfil da participação e das demandas no OP já nos últimos dois anos do último mandato petista, com um aprofundamento ainda mais significativo dessas diferenças quando Fogaça assume o governo.

\section{III.3. Empowerment, transparência e accounta- bility}

Em relação às variáveis empowerment, transparência e accountability, nosso principal método de investigação foram entrevistas com atores-chaves do programa do OP. Essas variáveis são de difícil quantificação, pois, em grande medida, dizem respeito às percepções sobre o andamento do programa ${ }^{12}$. Cabe frisar que um mecanismo claro de garantia de transparência no OP é a participação do representante da prefeitura nas reuniões do $\mathrm{OP}$, prestando contas à população sobre o padrão de gastos públicos ocorridos em anos anteriores. Assim, a própria metodologia do OP garante um mecanismo de transparência. Essa metodologia não mudou com o governo de Fogaça.

No quadro abaixo, transcrevemos a visão dos atores abordados quanto às mudanças no desempenho do programa de OP, especialmente após a saída do PT no governo. Apresentamos os resultados das entrevistas com representantes de entidades e associações que possuem um papel substancial no OP do município de Porto Alegre. As entrevistas foram sintetizadas a partir do posicionamento dos entrevistados quanto às mudanças no programa. Seus posicionamentos são resumidos abaixo com os seguintes indicadores: $(\boldsymbol{\Lambda})$ melhor desempenho da nova administração, $(\leftrightarrow)$ desempenho indiferente em ambos os governos e $(\boldsymbol{\nabla})$ pior desempenho da nova administração nas variáveis selecionadas.

TABELA 2 - PERCEPÇÃO DE ATORES SOCIAIS SOBRE PARTICIPAÇÃO, DEMANDAS, EMPOWERMENT, TRANSPARÊNCIA E ACCOUNTABILITYEM PORTO ALEGRE (2009)

\begin{tabular}{|c|c|c|c|c|c|}
\hline 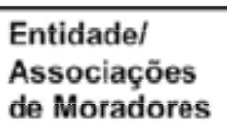 & Participação & Demandas & Empowerment & Transparência & Accountability \\
\hline Fracab & $\leftrightarrow$ & 7 & 7 & $\leftrightarrow$ & $\leftrightarrow$ \\
\hline Uampa & $\leftrightarrow$ & $\leftrightarrow$ & $\nabla$ & $\leftrightarrow$ & $\leftrightarrow$ \\
\hline ONG CIDADE & $\nabla$ & y & $\mathbf{Y}$ & $\overline{7}$ & $\nabla$ \\
\hline $\begin{array}{l}\text { Parque dos } \\
\text { Maias }\end{array}$ & $\boldsymbol{\nabla}$ & $\leftrightarrow$ & $\leftrightarrow$ & $\leftrightarrow$ & $\leftrightarrow$ \\
\hline Cavalhada & $\leftrightarrow$ & $\leftrightarrow$ & $\leftrightarrow$ & $\leftrightarrow$ & $\leftrightarrow$ \\
\hline Auxiliadora & $\nabla$ & $\nabla$ & $\nabla$ & $\nabla$ & $\nabla$ \\
\hline $\begin{array}{l}\text { Mario } \\
\text { Quintana- } \\
\text { Nacipaz }\end{array}$ & $\boldsymbol{T}$ & $\nabla$ & 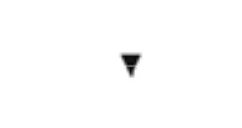 & $\nabla$ & $\mathbf{7}$ \\
\hline $\begin{array}{l}\text { Vila São Judas } \\
\text { Tadeu }\end{array}$ & $\leftrightarrow$ & $\leftrightarrow$ & $\leftrightarrow$ & $\leftrightarrow$ & $\leftrightarrow$ \\
\hline
\end{tabular}

FONTE: Rennó e Souza (2009).

Para os representantes das entidades, os dados de participação e sobre a execução das demandas

12 Uma alternativa metodológica para quantificar essas percepções seria utilizar amostras representativas dos atores envolvidos no processo e aplicar questionários estruturados com perguntas com escalas de resposta predefinidas. Contudo, não obtivemos financiamento para realização de tal survey. parecem refletir a realidade dos dados estatísticos apresentados. Prevalecem visões de queda na participação e de queda nas respostas às demandas. Em nenhum caso há percepções sobre melhoria nesses fatores com a administração Fogaça. Na melhor das hipóteses, alguns atores não vêem diferença entre as administrações.

No que se refere ao empowerment, também prevalecem visões negativas ou indiferentes. 
Lembra-se, traduzimos empowerment nas entrevistas como capacidade decisória dos atores envolvidos. Os entrevistados justificaram a queda ou indiferença baseados em duas categorias principais. Primeiro, os entrevistados mencionaram falta de organização popular nos movimentos de pressão política e da reduzida capacidade de intervenção no orçamento. $\mathrm{O}$ segundo fator mencionado são os poucos recursos disponibilizados pelo programa: pressupõe-se que quando há mais recursos, maior é o poder de decisão dos participantes. Por último, os entrevistados também mencionaram que uma reivindicação demandada e aprovada, mas não atendida, revela um poder de ação reduzido, característica que combinada à maior burocracia para a seleção das demandas a serem executadas aparenta ser um impeditivo para o maior empowerment da comunidade. Ou seja, a "tese do empowerment" enfatizada por Abers (1996), parece fragilizar-se no funcionamento do OP de Porto Alegre após 2004.

Já no que tange a transparência e accountability, prevalecem visões de indiferença entre os governos. Como a prefeitura permanece publicando os resultados orçamentários nos Planos de Investimentos, em que são apresentadas várias informações orçamentárias a respeito do OP, bem como a realização de prestação de contas nos encontros participativos para apresentação dos resultados, pode-se dizer que a transparência existe pelo menos na metodologia de funcionamento do OP. A visão de que não há mudanças, para a maioria das entidades confirma essa percepção. Ou seja, a manutenção da metodologia do OP nas duas administrações manteve os níveis de transparência idênticos. Se retomarmos os pontos de Wampler para a análise comparativa do OP, vemos no contraste das duas administrações em Porto Alegre que a metodologia do processo não sofreu grandes alterações.

\section{CONCLUSÕES}

A pesquisa do desempenho do OP portoalegrense ao longo de diversas gestões de governo revelou, primeiro, que o OP é sensível ao mandatário. Este possui influência, mesmo que indireta, de priorizar demandas que se relacionam à sua agenda política. Porém, embora se observem agendas distintas entre os governos, os resultados mostram claramente que os melhores resultados do programa foram sob o governo PT, que apresentou maior capacidade de atendimento de demandas, além de um maior número de participantes no programa. Também houve retrocessos na capacidade do programa de "empoderar" os cidadãos, entendido aqui como a capacidade dos mesmos de fazerem valer suas decisões. Todos esses indícios revelam uma transformação, uma metamorfose, não somente do público beneficiário do programa - que no passado concentrava-se nos setores mais pobres do município - mas também nos aspectos democráticos que levaram o OP a tornar-se um dos mecanismos de participação popular mais conhecidos no mundo.

Com base no estudo de caso de Porto Alegre, não há dúvida de que o desempenho e a efetividade do programa alterou-se nos últimos anos em diversos aspectos. Além disso, os fatos revelam que as primeiras gestões do OP obtiveram um índice melhor no que se propunham a realizar concluindo mais obras e obtendo maior adesão popular.

Entretanto, o ponto mais contundente de diferença entre o OP peemedebista e petista diz respeito ao perfil das demandas e à capacidade do estado de respondê-las. Os dados mostram claramente que o OP na atual gestão, mesmo sem estar enfrentando uma crise econômica, ainda apresenta resultados distintos dos índices alcançados pelo programa em anos anteriores, principalmente no que tange o tipo de demanda e a quantidade de obras acabadas.

Já no que tange à accountability e à transparência, o OP parece manter sua metodologia de divulgação dos resultados orçamentários e de prestação de contas dos gastos públicos. As percepções sobre "empoderamento", todavia, já sofreram oscilação maior, indicando que o programa mudou e para pior: isso é reflexo, na verdade, da queda de participação e da mudança nos padrões de investimento por meio do OP. Mais importante, parece refletir a diminuição no número de obras acabadas em anos recentes.

Em conclusão, os resultados indicam grande sensibilidade do programa à agenda política do partido no governo. Juntando-se esse achado à literatura comparada sobre o OP, fica claro que o programa peca por uma baixa institucionalização, que tornaria seu funcionamento mais uniforme nas diferentes administrações. A dependência na participação de populares tampouco pode ser 
tomada como uma constante, já que a existência do programa não garante, automaticamente, adesão de grandes parcelas da população. A participação, tão vital para o programa, tem de ser nutrida com bons resultados, realizados por meio da conclusão de obras e, dessa forma, do fortalecimento das percepções de empowerment.

Lúcio Rennó (luciorenno7@gmail.com) é Doutor em Ciência Política pela University of Pittsburgh (EUA) e Professor de Ciência Política na Universidade de Brasília (UnB).

Aílton de Souza (ailton2006@uol.com.br) é Mestre em Estudos Comparados sobre as Américas pela Universidade de Brasília (UnB) e Professor de Antropologia e Sociologia na Universidade Estadual do Oeste do Paraná (Unioeste).

\section{REFERÊNCIAS BIBLIOGRÁFICAS}

ABERS, R. 1996. From Ideas to Practice: The Partido dos Trabalhadores and Participatory Governance in Brazil. Latin American Perspectives, Oxford, v. 23, n. 4, p. 35-53, Autumn.

1997. Inventando a democracia: distribuição de recursos públicos através da participação popular em Porto Alegre. Porto Alegre: ONG Cidade.

2000. Inventing Local Democracy: Grassroots Politics in Brazil. Colorado: L. Rienner.

AVRITZER, L. 2003. O orçamento participativo e a Teoria Democrática: um balanço crítico. In: AVRITZER, L. \& NAVARRO, Z. (orgs.). A inovação democrática no Brasil: o orçamento participativo. São Paulo: Cortez. Disponível em: http://www.democracia participativa.org/files/LeonardoAvritzerOor\%E7amentoparticipativoeateoriademocr\% E1ticaumbalan\%E7ocr\%EDtico.pdf. Acesso em: 21.dez.2011.

2006. New Public Spheres in Brazil: Local Democracy and Deliberative Politics, International Journal of Urban and Regional Research, Oxford, v. 30, n. 3, p. 623-637, Sep.

2007. Sociedade civil, instituições participativas e representação: da autorização à legitimidade da ação. Dados, Rio de Janeiro, v. 50, n. 3, p. 443-464, jan. Disponível em: http://www.scielo.br/pdf/dados/v50n3/01.pdf. Acesso em: 21.dez.2011.

2008. Instituições participativas e desenho institucional: algumas considerações sobre a variação da participação no Brasil democrático. Opinião Pública, Campinas, v. 14, n. 1, p.43-
64, jun. Disponível em: http://www.scielo.br/ scielo.php? script $=$ sci_pdf\&pid $=$ S0 104 $62762008000100002 \& \operatorname{lng}=$ en\&nrm=iso\&tlng=pt. Acesso em: 21.dez.2011.

AVRITZER, L. \& COSTA, S. 2004. Teoria crítica, democracia e esfera pública: concepções e usos na América Latina. Dados, Rio de Janeiro, v. 47, n. 4, p.703-728. Disponível em: http://www.scielo.br/pdf/ dados/v47n4/a03v47n4.pdf. Acesso em: 21.dez.2011.

AVRITZER, L. \& PEREIRA, M. D. 2005. Democracia, participação e instituições híbridas. Teoria e Sociedade, Belo Horizonte, Número Especial, p. 16-41, maio. Disponível em: http://www.democraciaparticipativa.org/ files/TeoriaeSociedade NumeroEspecial marco2005_InstituicoesHibridaseParticipacaono BrasilenaFranca.pdf. Acesso em: 21.dez.2011.

BABBIE, E. 2004. The Practice of Social Research. 10 $0^{\text {th }}$ ed. Belmont: Thomson.

BAIERLE, S. 2003. The Porto Alegre Thermidor? "Participatory Budget" at the Crossroads. Socialist Register, Pontypool, v. 39, p. 300322.

2005. Porto Alegre em transe. Porto Alegre: ONG Cidade.

2007. Lutas urbanas em Porto Alegre: entre a revolução política e o transformismo, Porto Alegre: ONG Cidade.

2008. A experiência brasileira em Orçamento Participativo $(O P)$ : o caso de Porto Alegre. Trabalho apresentado no Seminário de Lançamento da REDE URB-AL N ${ }^{\circ} 9$, "Financiamento Local e Orçamento 
Participativo", Porto Alegre, Prefeitura Municipal de Porto Alegre. Digit.

BAIOCCHI, G. 2003. Participation, Activism, and Politics: The Porto Alegre Experiment. In: FUNG, A. \& WRIGTHT, E. (eds.) Deepening Democracy Institutional Innovations in Empowered Participatory Governance. London: Verso.

BIDERMAN，C. \& SILVA, G. P. 2007. Estimating the Impact of Participatory Budget on Observed Outcomes. Trabalho apresentado no $35^{\circ}$ Encontro Nacional de Economia, Recife. Digit. Disponível em: http:// www.anpec.org.br/encontro2007/artigos/ A07A070.pdf. Acesso em: 21.dez.2011.

CABBANES, Y. 2004. Participatory Budgeting: a Significant Contribution to Participatory Democracy. Environment and Urbanization, Thousand Oaks, v. 16, n. 1, p. 27-46, Apr. Disponível em: http://www.environmentand urbanisation.org/documents/16-1pp2746cabannes.pdf. Acesso em: 21.dez.2011.

DAGNINO, E.; OLVERA, A. J. \& PANFICHI, A. (orgs.). 2006. A disputa pela construção democrática na América Latina. São Paulo: Paz e Terra.

2007. Innovación democrática en América Latina: una primera mirada al proyecto democrático-participativo. Trabalho apresentado no Seminário Democratic Innovation in the South, San José, Costa Rica, Mar. Digit. Disponível em: http://bibliotecavirtual. clacso.org.ar/ar/libros/sursur/democra/ 05dag.pdf. Acesso em: 21.dez.2011.

DIAS, M. R. 2004. Da capilaridade do sistema representativo: em busca da legitimidade nas democracias contemporâneas. Civitas, Porto Alegre, v. 4, n. 2, p. 235-256, jul.-dez. Disponível em: http://redalyc.uaemex.mx/pdf/ 742/74240203.pdf. Acesso em: 21.dez.2011.

2008. Desejo de mudança: das motivações e razões que levaram à derrota do PT em Porto Alegre nas eleições de 2004. Civitas, Porto Alegre, v. 8, n. 2, p. 237-257, maio-ago. Disponível em: http://revistaseletronicas. pucrs.br/ojs/index.php/civitas/article/viewFile/ 4762/3824. Acesso em: 21.dez.2011.
FEDOZZI, L. 2001. Práticas inovadoras de gestão urbana: o paradigma participativo. Revista Paranaense de Desenvolvimento, Curitiba, $\mathrm{n}$. 100, p. 93-105, jan.-jun. Disponível em: http:/ /www.ipardes.pr.gov.br/ojs/index.php/ revistaparanaense/article/download/227/188. Acesso em: 21.dez.2011.

2005. Participação nos governos locais do Brasil contemporâneo. Cadernos FLEM, Salvador, n. 8, p. 136-168. Disponível em: http://www.flem.org.br/paginas/cadernos flem/pdfs/CadernosFlem8-VersaoCompleta. pdf. Acesso em: 21.dez.2011.

2007. Observando o Orçamento Participativo de Porto Alegre: análise histórica de dados: perfil social e associativo, avaliação e expectativas. Porto Alegre: Tomo.

GOHN, M. G. 2004. Movimentos sociais no início do século XXI: antigos e novos atores sociais. Petrópolis: Vozes.

NYLEN, W. R. 2002. Testing the Empowerment Thesis: The Participatory Budget in Belo Horizonte and Betim. Journal of Comparative Politics, New York, v. 34, n. 2, p. 127-145, Jan.

2003. An Enduring Legacy? Popular Participation in the Aftermath of the Participatory Budgets of João Monlevade and Betin. In: BAIOCCHI, G. (ed.) Radicals in Power: The Workers Party (PT) and Experiments in Urban Democracy in Brazil. London: Zed.

RENNÓ, L. 2006. Os militantes são mais informados? Desigualdade e informação política nas eleições de 2002. Opinião Pública, Campinas, v.12, n. 2, p. 329-347, nov. Disponível em: http://www.scielo.br/pdf/op/ v12n2/05.pdf/. Acesso em: 21.dez.2011.

RENNÓ, L. \& AMES, B. 2010. Participatory Budgeting, Political Discussion Networks and Political Information in Two Brazilian Cities. In: WOLF, M.; MORALES, L. \& KEN'ICHI, I. (eds.). Political Discussion in Modern Democracies: A Comparative Perspective. London: Routledge.

RENNÓ, L. \& SOUZA, A. 2009. Entrevistas dos autores com as entidades e associações de bairro. 
RIBEIRO, A. \& GRAZIA, G. 2003. Experiência do orçamento participativo no Brasil: Período de 1997-2000. Petrópolis: Vozes.

ROWLANDS, J. 1995. Empowerment Examined. Development in Practice, London, v. 5, n. 2, p. 101-107, May.

SANTOS, B. S. 1998. Participatory Budgeting in Porto Alegre: Toward a Redistributive Democracy. Politics \& Society, Thousand Oaks, v. 26, n. 4, p. 461-510, Dec.

SANTOS, W. G. 1993. Fronteiras do Estado mínimo: indicações sobre o híbrido institucional brasileiro. In: Razões da desordem. Rio de Janeiro: Rocco.

SCHNEIDER, A. \& GOLDFRANK, B. 2006. Construción institucional competitiva: el PT el presupuesto participativo de el Rio Grande do Sul. In: WANDERLEY LUMBAMBO, C.; BANDEIRA COELHO, D. \& MELO, M. A. Diseno institucional y participación politica: experiência en el Brasil contemporâneo. Buenos Aires: Clacso.

SOUZA, C. 2001. Construção e consolidação de instituições democráticas: o papel do orçamento participativo. São Paulo em Perspectiva, São Paulo, v. 15, n. 4, p. 84-97, out.-dez. Disponível em: http://www.scielo.br/ $\mathrm{pdf} / \mathrm{spp} / \mathrm{v} 15 \mathrm{n} 4 / 10375 . \mathrm{pdf}$. Acesso em: 21.dez.2011.

SPADA, P. 2009. The Economic and Political Effects of Participatory Budgeting. Trabalho apresentado no Congress of the Latin American Studies Association, Rio de Janeiro, jun. Disponível em: http://lasa.international.pitt.edu/ members/congress-papers/lasa2009/files/ SpadaPaolo.pdf. Acesso em: 21.dez.2011.

TATAGIBA, L. 2006. Os desafios da articulação entre sociedade civil e sociedade política sob o marco da democracia gerencial. O caso do projeto rede criança em Vitória/ES. In: DAGNINO, E.; OLVERA, A. \& PANFICHI, A. (orgs.). A disputa pela construção democrática na América Latina. São Paulo: Paz e Terra.
TEIXEIRA, A. C. (org.). 2003. Orçamento participativo: democratização da gestão pública e controle social. Rio de Janeiro: Fórum Nacional de Participação Popular.

TEIXEIRA, A \& ALBURQUERQUE, M. 2006. Orçamentos participativos: projetos políticos, partilha de poder e alcance decisório. In: DAGNINO, E.; OLVERA, A. \& PANFICHI, A. (orgs.). A disputa pela construção democrática na América Latina. São Paulo: Paz e Terra.

WAMPLER, B. 2003. Orçamento participativo: uma explicação para as amplas variações nos resultados. In: AVRITZER, L. \& NAVARRO, Z. (orgs.). A inovação democrática no Brasil: o orçamento participativo. São Paulo: Cortez.

2006. Expandiendo la responsabilidad en la gestión por medio de instituciones participativas: activistas y reformistas en los munícipios brasileños. In: WANDERLEY LUMBAMBO, C.; BANDEIRA COELHO, D. \& MELO, M. A. (orgs). Diseno institucional y participación politica: experiência en el Brasil contemporâneo. Buenos Aires: Clacso

2007. A Guide to Participatory Budgeting. In: SHAH, A. (ed.). Participatory Budgeting. Washington (DC): World Bank.

2008. A difusão do orçamento participativo brasileiro: "boas práticas" devem ser promovidas? Opinião Pública, Campinas, v. 14, n. 1, p. 65-95, jun. Disponível em: http:// www.scielo.br/pdf/op/v14n1/03.pdf. Acesso em: 21.dez.2011.

WAMPLER，B. \& AVRITZER，L. 2004. Participatory Publics: Civil Society and New Institutions in Democratic Brazil. Jornal of Comparative Politics, New York, v. 36, n. 3, p. 291-312, Apr.

ZAMBONI, Y. Participatory Budgeting and Local Governance: an Evidence-Based Evaluation of Participatory Budgeting Experiences in Brazil. Bristol. Dissertação (Mestrado em Public Policy). University of Bristol. Disponível em: http://siteresources.worldbank.org/ INTRANETSOCIALDEVELOPMENT/ Resources/Zamboni.pdf. Acesso em: 21.dez.2011. 


\section{OUTRASFONTES}

BANCO MUNDIAL. 2008. Para um orçamento participativo mais inclusivo e efetivo em Porto Alegre. Relatório n. 40144-BR. Washington (DC): Banco Mundial. Disponível em: http:// siteresources.worldbank.org/INTBRAZIL/ Resources/OP_port.pdf. Acesso em: 21.dez.2011.

Rumo a um orçamento participativo mais inclusivo e efetivo em Porto Alegre. Relatório Sumário de um Estudo de Caso, Washington (DC).

BRASIL. SECRETARIA DE ORÇAMENTO FEDERAL. 2003. Vinculações de receitas dos orçamentos fiscal e da seguridade social e o poder discricionário de alocação dos recursos do Governo Federal. Brasília: Ministério do Planejamento, Orçamento e Gestão. Disponível em: http://www.planejamento.gov.br/ secretarias/upload/Arquivos/sof/publicacoes/ vinculacoes_orcamentarias.pdf. Acesso em: 21.dez.2011.

PREFEITURA MUNICIPAL DE PORTO ALEGRE. 1992. Plano de Investimentos 1992. Porto Alegre: Prefeitura Municipal de Porto Alegre.

1993. Plano de Investimento 1993. Porto Alegre: Prefeitura Municipal de Porto Alegre.

1996. Plano de Investimento 1996. Porto Alegre: Prefeitura Municipal de Porto Alegre.

1998. Plano de Investimento 1998. Porto Alegre: Prefeitura Municipal de Porto Alegre.
1999. Plano de Investimento 1999. Porto Alegre: Prefeitura Municipal de Porto Alegre.

2001. Plano de Investimento 2001. Porto Alegre: Prefeitura Municipal de Porto Alegre.

2002. Plano de Investimento 2002. Porto Alegre: Prefeitura Municipal de Porto Alegre.

2003. Plano de Investimento 2003. Porto Alegre: Prefeitura Municipal de Porto Alegre.

2004. Plano de Investimento 2004. Porto Alegre: Prefeitura Municipal de Porto Alegre.

2005. Plano de Investimento 2005. Porto Alegre: Prefeitura Municipal de Porto Alegre.

2006. Plano de Investimento 2006. Porto Alegre: Prefeitura Municipal de Porto Alegre.

2007. Plano de Investimento 2007. Porto Alegre: Prefeitura Municipal de Porto Alegre.

2008. Plano de Investimento 2008. Porto Alegre: Prefeitura Municipal de Porto Alegre. 2009. Regimento Interno do OP. Porto Alegre: Prefeitura Municipal de Porto Alegre.

2009. Orçamento Participativo: 20 Anos. Publicação Especial, ago. Porto Alegre: Prefeitura Municipal de Porto Alegre.

2011. Orçamento Participativo. Acompanhamento de obras e serviços. Porto Alegre: Prefeitura Municipal de Porto Alegre. Disponível em: http://www.portoalegre.rs.gov. br/op_prestacao/acomp.asp/. Acesso em: 21.dez.2011. 


\section{THE METAMORPHOSIS OF PARTICIPATORY BUDGETING: CHANGE OF GOVERNMENT AND ITS EFFECTS IN PORTO ALEGRE}

Lúcio Rennó and Aílton Souza

The different participatory experiences emerging in Brazil during the decade of the 1990s came together, as Tatagiba has argued, in turning the country into "a hotbed of innovative management experiences". One outstanding experience is the Participatory Budgeting Orçamento Participativo (OP) Program, which over the course of the years has been the stage of intense debate and study, garnering both admirers and critics. Yet notwithstanding its fame and the many studies that have been made of it, few researchers have sought to evaluate the program's performance and sensitivity to municipal government. This article examines the participatory budget program in Porto Alegre within the period spanning 1989 to 2008, making specific analysis of the program's sensitivity to changes in administration, that is, from the Workers' Party (Partido dos Trabalhadores (PT)) between 2001-2004 to the PMDB (Party of the Brazilian Democratic Movement or Partido do Movimento Democrático Brasileiro) from 2005-2008. In other words, we ask whether the change in the political party at the head of city government made a difference in terms of program performance. Our analysis indicates that the program has been highly influenced by the political party responsible for its implementation. This can be seen as evidence of low levels of institutionalization, even in the municipality where the program has been most successful, that is, in Porto Alegre.

KEYWORDS: Participatory Budgeting; Evaluation of Public Policy; Porto Alegre. 